\title{
La migración digital y la crítica situación de la prensa y televisión marcan el ecosistema informativo de Castilla y León
}

\author{
Dra. Clara Sanz Hernando|cshernando@ubu.es \\ Universidad de Burgos
}

\author{
Palabras clave \\ Castilla y León, ecosistema informativo, prensa, \\ medios digitales, radio, RTVCYL. \\ Sumario \\ 1. Introducción. 2. Metodología y fuentes utilizadas. 3. \\ Cambios cuantitativos y cualitativos en el mapa \\ mediático. 4. Desempleo y precariedad laboral 5 . \\ Conclusiones. 6. Bibliografía.
}

\section{Resumen}

La industria de los medios de comunicación de Castilla y León ha experimentado grandes cambios desde que en 2008 les afectara, al igual que al conjunto del sector, la crisis económica y la de su propio modelo de negocio. Este trabajo se propone elaborar el mapa mediático resultante de estos críticos años, conocer la situación actual de las empresas periodísticas en las nueve provincias que conforman esta Comunidad, la migración digital que se ha producido y las consecuencias que este terremoto ha tenido para el conjunto de los profesionales de la comunicación. La puesta en marcha de una labor de campo descriptiva, contrastada con entrevistas y encuestas realizadas a empresas y trabajadores del sector, ha permitido medir el alcance de estas transformaciones. Las conclusiones obtenidas constatan la debilidad y el declive de la prensa impresa y el auge de los diarios digitales; la reestructuración televisiva; la estabilidad de la radio; la creciente concentración de medios en los Grupos Promecal y Edigrup Media, y la devastadora destrucción de empleo.

\section{Cómo citar este texto:}

Clara Sanz Hernando (2017): "La migración digital y la crítica situación de la prensa y televisión marcan el ecosistema informativo de Castilla y León”, en Miguel Hernández Communication Journal, nº, pp. 617 a 642. Universidad Miguel Hernández, UMH (ElcheAlicante). Recuperado el $\_$de de 20 de: link del artículo en mhjournal.org] 


\section{The shift towards digital media and the critical state of press and television set the information ecosystem of Castille and Leon}

Dra. Clara Sanz Hernando|cshernando@ubu.es

Universidad de Burgos

\section{Keywords}

Castille and Leon, information ecosystem, press, digital media, radio, RTVCYL.

\section{Summary}

1. Introduction. 2. Methodology and sources used. 3. Quantitative and qualitative changes in the media map. 4. Unemployment and job insecurity 5. Conclusions. 6. Bibliography.

\section{Abstract}

The media industry in Castille and Leon have experienced substantial change since 2008 , as a consequence of both the economic crisis and the crisis of their business model. This work aims to map the media during this critical time, and to examine the current state of the media companies of the nine provinces of this community, the migration to digital media, and the consequences of these dramatic changes to the media professionals. The magnitude of these transformations was assessed by field

work comprised of interviews and surveys to businesses and employees of this sector. The results show the fragility and decline of the written press, the upsurge of digital media, the restructuring of television, the stability of radio, the loss of jobs, and the growing concentration of media in the Promecal and Edigrup Media.

\section{How to cite this text:}

Clara Sanz Hernando (2017): "The shift towards digital media and the critical state of press and television set the information ecosystem of Castille and Leon", en Miguel Hernández Communication Journal, n⿳8, pp. 617 to 642, Universidad Miguel Hernández, UMH (Elche-Alicante). Accessed 20_ in: [paper link in mhjournal.org] 


\section{Introducción}

Castilla y León, con sus 2.445.666 vecinos, es la sexta Comunidad Autónoma de España. Sus $94.222 \mathrm{Km} 2$ de superficie la convierten en la más extensa del país y de Europa, lo que hace que su densidad de población sea muy baja, 26 habitantes por $\mathrm{km} 2$, cuando la media española está en 81 . Este es el marco geográfico al que circunscribimos este trabajo que se propone realizar un censo de los medios de comunicación existentes, un mapa actualizado de los diarios impresos y digitales, de las radios y de las televisiones que comparten mercado en las nueve provincias que forman parte de este territorio.

El problema con el que se enfrenta la recogida de datos es que no existe ninguna fuente oficial que los proporcione. La única publicación que venía recopilando una relación anual de medios era la Guía de la Comunicación de Castilla y León, que dejó de editar la Junta en 2009. A pesar de que desde entonces los listados se cargan en su portal web, lo cierto es que no están actualizados. Ello nos obliga a llevar a cabo una labor de campo descriptiva para obtener una relación fiable que permita conocer qué medios siguen presentes, cuántos han desaparecido y qué otros se han abierto camino. Además, esta investigación pretende profundizar en la estructura mediática de Castilla y León y sus transformaciones.

La región no dispone de un Observatorio de la Comunicación que hubiera permitido un seguimiento continuado y sistemático de las novedades producidas en el ecosistema mediático, de ahí la necesidad de estudios de esta naturaleza, que permiten poner al día la evolución de los mass media regionales.

La historiografía sobre el particular es escasa. El estudio más completo, por ser el único que analiza de forma conjunta los medios impresos y audiovisuales, data de 2008 y se hizo a iniciativa del Consejo Económico y Social de Castilla y León. El equipo redactor del informe "La relevancia de los medios de comunicación en Castilla y León”, coordinado por Celso Almuiña, realizó un completo y exhaustivo análisis de situación. Desde entonces, no se ha efectuado revisión alguna, cuestión que creemos necesario encarar en un momento en el que el sector, al igual que otros muchos, ha debido hacer frente tanto a la crisis económica que se inició en España ese mismo año 2008 como a la crisis de su propio modelo de negocio, con la irrupción de Internet y el periodismo digital. La evolución ha sido vertiginosa, y en poco tiempo se ha pasado de considerar al periodismo digital como una adaptación de las noticias impresas utilizando la tecnología digital (Gómez-Escalonilla, 2004: 61) 
a toda una especialidad que se bate en el ciberespacio para crear nuevos contenidos capaces de dar la vuelta al mundo.

Otros trabajos sobre los medios de comunicación en Castilla y León, que repasamos a continuación por su interés, pero que distan del objetivo que nos proponemos, han incidido de forma monográfica en alguno de los sectores, como el audiovisual que analizan Ortega (2006) y Badillo (2003) profundizando en los orígenes de la televisión local. El segundo propone el concepto de "televisión subnacional" (Badillo, 2011: 65), donde quedarían englobados los fenómenos audiovisuales que se producen en áreas de cobertura inferiores a la nacional. Las dimensiones de las televisiones autonómicas no son equiparables a las locales, pero considera que han de estudiarse conjuntamente porque el ámbito competencial es el mismo, el autonómico, lo que permite comprender su desarrollo como parte de un diseño conjunto en el nivel regional.

A Zulima Iglesias (2006: 212), que se ha detenido en los contenidos de las televisiones locales, le sorprende el poco interés que muestran por la información regional, así como "la mediocridad" de los noticiarios, especialmente en la utilización de fuentes y el contraste de la información. Recientemente, Marta Pérez (2015) se ha centrado en los orígenes y la evolución del Centro Territorial de TVE en Castilla y León. Una de las conclusiones a las que llega es que la información de proximidad cada vez es más escasa y se le dedica menos tiempo, cuestión plenamente coincidente con lo que viene pasando en el medio radiofónico.

Profesores de la IE University investigaron la estructura radiofónica de Castilla y León y las programaciones locales y regionales de las diferentes emisoras privadas (Díaz-González et al., 2008; González del Valle et al., 2010). Tras un detenido análisis, comprobaron que, efectivamente, el recorte de las emisiones locales era una realidad. No distaba mucho de lo que ocurría, pero acrecentado, en RNE 5 Todo Noticias (Chomón, 2011: 85), donde la programación local de la radio pública sufrió un severo retroceso de 1994, año en el que se puso en marcha, a 2010. La programación local pasó de ocupar 115 minutos diarios a situarse en 15 .

\section{Metodología y fuentes utilizadas}

Para actualizar el censo de medios de comunicación hemos partido de la Guía de la Comunicación 2009, la última editada, como hemos comentado, por la Junta de Castilla y León. Esta tarea ha requerido un importante trabajo de campo, pues actualmente no hay ninguna fuente oficial ni profesional que 
disponga de estos datos. Hemos optado por realizar entrevistas telefónicas con los departamentos de comunicación de las delegaciones territoriales de la Comunidad Autónoma, conocedores del ecosistema mediático provincial por ser los responsables de las relaciones externas. La información facilitada fue sometida a contraste con otros departamentos de comunicación institucionales.

Un rastreo a través de Internet permitió acceder a varias webs con la relación de medios, pero en muchos casos este listado estaba incompleto, desfasado o incluso era erróneo, por lo que ha sido imprescindible entrar en contacto con los propios medios de comunicación para asegurar la fiabilidad que debe tener un trabajo de estas características. Igualmente, ha sido indispensable manejar otras fuentes como la del Colegio Oficial de Periodistas de Castilla y León, la Asociación de la Investigación de Medios de Comunicación, AIMC; la Oficina de Justificación de la Difusión, OJD; la Sociedad General de Autores y Editores, SGAE; Kantar Media; la revista Noticias de la Comunicación, así como diversos informes y anuarios de diferentes empresas y colectivos. Herramientas todas ellas que nos han permitido abrir nuestro campo de investigación, superar el análisis cuantitativo y ahondar en los cambios que se han producido en la estructura mediática.

Precisamos que el censo que elaboramos reúne los periódicos de carácter generalista y no especializados, de periodicidad diaria, semanal o mensual, tanto de pago como gratuitos, y que no se han tenido en cuenta sus corresponsalías. En medios digitales, solo se han contabilizado los que responden a este formato, y no los que siendo impresos tienen su correspondiente portal web. En radio, se recogen las emisoras que pertenecen a los grandes grupos nacionales, tanto las privadas como las públicas. Y en lo concerniente a televisión, señalamos que por lo que se refiere a Radio Televisión Castilla y León, RTVCYL, se han registrado sus ubicaciones provinciales, no así las de RTVE, pues la presencia provincial del ente público, salvo en Valladolid, se asemeja al papel de los corresponsales de otros medios de comunicación.

\section{Cambios cuantitativos y cualitativos en el mapa mediático}

Los lectores de diarios han bajado considerablemente en Castilla y León. Sobre el total de la población, su consumo ha pasado de representar el 43,2\% en 2009 al 34,3\% en 2016 (AIMC, 2010, 2017). Actualmente, esta Comunidad ocupa la sexta posición dentro del conjunto nacional, cuya media se encuentra en el 26,5\%. En estos años, se ha producido también un descenso en la 
audiencia de televisión, pero mucho menos acusado, del 91,1\% al 90,2\%. Los televidentes casi triplican a los lectores de prensa: 9 de cada 10 castellanos y leoneses ven televisión. Los oyentes de radio han aumentado en el periodo que analizamos, pues han evolucionado del 57,1\% al 63,9\%, lo que sitúa a Castilla y León por encima de la media, que es del 60\%. Con todo, el crecimiento más espectacular se ha producido en Internet. No obstante, pese a que su consumo se ha duplicado con creces - del 30,5\% al 67,6\%-, Castilla y León está aún por debajo del 71,9\% de la media nacional -ocupa la duodécima posición-.

Conviene recordar que el 77,5\% de los hogares de Castilla y León ya tiene Internet (Fundación Telefónica, 2016) y que cada vez son más los internautas que navegan de forma regular por la web (71,5\%). Los que se conectan a través de sus smartphones han crecido en más de 30 puntos en los últimos tres años y ahora alcanzan el 88,9\%.

\subsection{La caída de la prensa diaria}

El número de periódicos ha retrocedido y ha pasado de los 50 que se contabilizaban en 2009 a los 42 de 2016 (Gráfico 1). La provincia que cuenta con un mayor número es la capital de la región, Valladolid, con ocho (El Norte de Castilla, Diario de Valladolid-El Mundo, las delegaciones de Abc y La Razón, El Día de Valladolid (semanal), La Voz de Medina (semanal), El Nuevo Arroyo (quincenal gratuito) y La Mar de Campos (mensual y con distribución en Valladolid, León y Zamora). León reúne siete: Diario de LeónEl Mundo, La Nueva Crónica, El Día de León (semanal), El Faro Astorgano (sale 5 días a la semana), El Adelanto Bañezano y La Bañeza Hoy (semanales), y Gente en León (gratuito semanal). Burgos oferta seis publicaciones: Diario de Burgos, El Correo de Burgos-El Mundo, El Correo-edición Miranda de Ebro, los gratuitos semanales Gente en Burgos y Miranda Informa y el gratuito mensual Crónica de las Merindades.

Segovia ocupa la cuarta posición, con cinco (El Adelantado de Segovia, la edición de El Norte de Castilla, El Día de Segovia (semanal), y los mensuales El Nordeste de Segovia y Segovia Noticias. Palencia y Salamanca mantienen cuatro. En la provincia palentina conviven Diario Palentino-El Día de Palencia, la edición de El Norte de Castilla, Carrión (quincenal) y el gratuito La Gaceta de Palencia. En Salamanca, La Gaceta Regional de Salamanca, la edición de El Norte de Castilla, el semanal El Día de Salamanca y el gratuito Dgratis Salamanca. En Soria, se contabilizan tres: Heraldo de Soria, Diario de Soria-El Mundo y el semanal El Día de Soria, los mismos que en Zamora: La Opinión-El Correo de Zamora, El Día de Zamora (semanal) y Ahora 
Benavente (quincenal). Ávila cierra este listado con Diario de Ávila y el gratuito mensual Abulenses.es.

\section{Gráfico 1. Diarios impresos en Castilla y León 2009-2016}

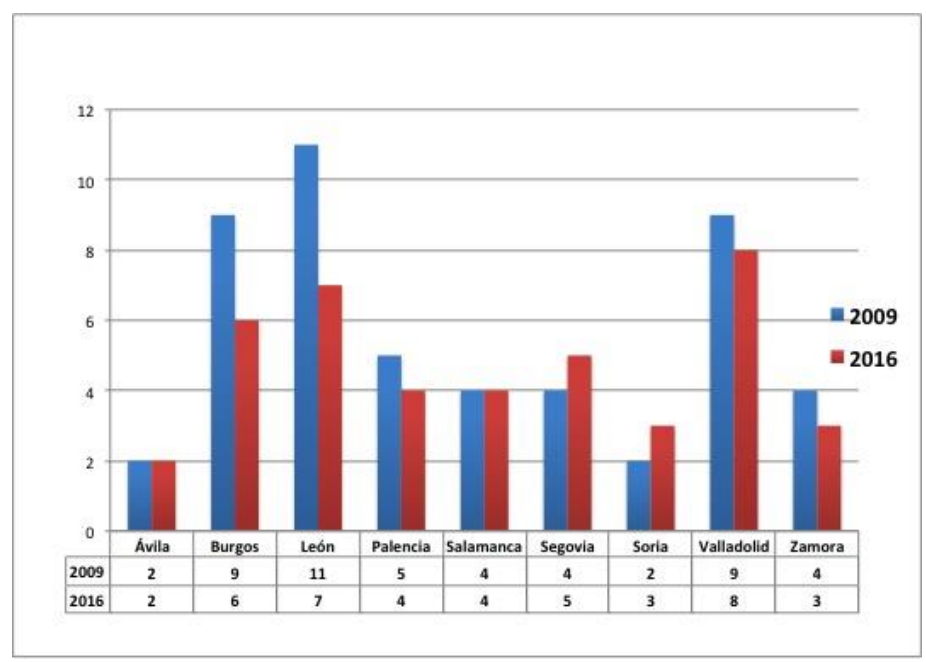

Fuente: Elaboración propia.

Todas las provincias cuentan con una cabecera diaria, algunas centenarias. En la capital del Pisuerga se editan las que tienen una vocación regional, como El Norte de Castilla, decano de la prensa diaria española perteneciente al Grupo Vocento, que además tiene ediciones provinciales en Palencia, Segovia y Salamanca -la que venía publicando en Zamora desde 1992 cerró en septiembre de 2010-; el Diario de Valladolid-El Mundo, del Grupo Begar, denominado hoy Edigrup Media y creado por el constructor leonés José Luis Ulibarri a partir de los periódicos locales implantados por El Mundo en la región; y las delegaciones regionales de Abc -Grupo Vocento-, y La Razón Grupo Planeta-.

Algunas de las cabeceras diarias de orientación provincial y local pertenecen al Grupo Promecal, Promotora de Medios de Castilla y León, propiedad del constructor burgalés Antonio Miguel Méndez Pozo. Es el caso de Diario de Ávila, Diario de Burgos, Diario Palentino y un 8\% desde 2015 -antes un 25\%de la sociedad editora de El Adelantado de Segovia, cuyo control se mantiene desde su nacimiento en 1901 en manos de la familia de su fundador, Rufino Cano de Rueda (Díaz, 2006: 1364). Primeras marcas provinciales son también Diario de León, de Edigrup Media; Heraldo de Soria, editado por el Grupo 
Heraldo desde 1997; La Opinión-El Correo de Zamora, de Prensa Ibérica, hegemónico en esta provincia, y La Gaceta Regional de Salamanca, del Grupo Promotor Salmantino.

Precisamente, ha sido la provincia de Salamanca una de las más castigadas por la crisis que el sector ha venido sufriendo durante los últimos años. Su diario decano, fundado en 1883, El Adelanto, cerró en mayo de 2013. La medida afectó a su edición zamorana y supuso el despido de 30 personas. Dos años antes, en 2011, había dejado de publicarse Tribuna de Salamanca, la tercera cabecera provincial que se mantuvo en los quioscos durante 17 años. Fueron despedidos 32 trabajadores y los salmantinos pasaron de disponer tres diarios a uno. El Norte de Castilla aprovechó este vacío y abrió una nueva edición en la provincia charra en septiembre de 2013, pocos meses después de la desaparición de El Adelanto.

La crisis se llevó también a La Crónica de León, que se despidió con un "León, adiós y hasta siempre" en la portada de su último número, de 31 julio de 2013. Tras 27 años, la publicación cerraba con 29 empleados en activo, pero en la que habían llegado a estar en nómina más de 70. En noviembre de ese mismo año, el Grupo Carflor editó La Nueva Crónica, que se distribuye conjuntamente con Abc.

Promecal puso en marcha en 2015 un nuevo proyecto editorial, de carácter regional, con la apertura de semanarios en algunas provincias de la región León, Salamanca, Segovia y Soria- teniendo al Día de Valladolid como cabecera matriz. El diario vallisoletano, que se fundó en el año 2000, intentó hacerse hueco como diario sin conseguirlo. Pasó a ser gratuito saliendo cinco días a la semana, y actualmente se ha reconvertido a semanario de pago.

En cuanto a los semanarios gratuitos, el veterano Gente ha retirado la edición de las provincias de Ávila, Palencia, Segovia y Valladolid, mientras que mantiene las de Burgos -donde comenzó- y León. Un nuevo intento de prensa regional gratuita lo constituye EPCYL, El Periódico de Castilla y León, que desde noviembre de 2015 ha firmado acuerdos con diferentes rotativos provinciales, en formato papel y digital, para llegar a todos los rincones de la Comunidad. 
Gráfico 2. Difusión de los diarios en Castilla y León 2007-2015

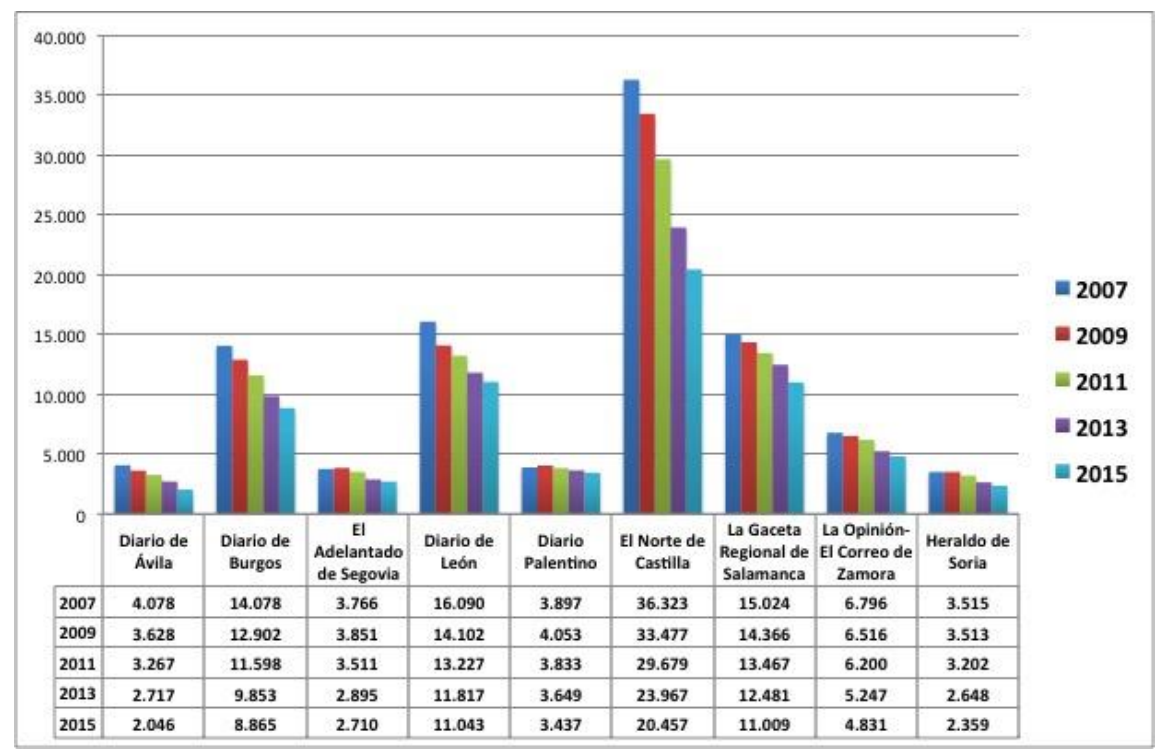

Fuente: Elaboración propia con datos de la Oficina de Justificación de la Difusión (OJD) y Noticias de la Comunicación, números 296, 307, 318, 329, 340, 351, 362 y 373. Promedio diario.

La difusión de los diarios (Gráfico 2) ha sufrido un fuerte revés de 2007 a 2015. La de Diario de Ávila se redujo prácticamente a la mitad, 49,9\%, seguida por El Norte de Castilla, que acabó 2015 con un 43,7\% menos. Diario de Burgos es el tercer diario que más lectores ha perdido, un 37,1\%, seguido de Heraldo de Soria, 32,9\% y Diario de León, 31,4\%. Con una erosión similar en las cifras de audiencia se encuentran La Opinión-El Correo de Zamora, 29,0\%, el Adelantado de Segovia, 28,0\%, y La Gaceta Regional de Salamanca, 26,7\%. Quien menos lectores dejó por el camino fue Diario Palentino, un $11,8 \%$ menos.

Castilla y León no conserva ningún diario con una difusión superior a los 25.000 ejemplares. El Norte de Castilla sí la tuvo hasta 2013, cuando bajó y se situó entre los de 10.000 y 25.000 ejemplares. La misma suerte corrió Diario de Burgos, que ese mismo año descendió de rango y se colocó entre los que estaban por debajo de los 10.000. Actualmente, solo 3 periódicos -El Norte de Castilla, La Gaceta Regional de Salamanca y Diario de León- están entre los 10.000 y 25.000, y el resto se encuentra lejos de los 10.000 ejemplares. 
La cifra de negocio de estos diarios ha disminuido en el tramo 2012-2015 y algunos presentan un resultado negativo, como El Adelantado de Segovia, La Opinión-El Correo de Zamora y el Heraldo de Soria (Tabla 1). Los ingresos por venta de ejemplares y por publicidad han tenido diferentes desarrollos, pero los que sí han decrecido en estas dos magnitudes año tras año han sido Diario de Ávila, Diario de Burgos, El Adelantado de Segovia y La Opinión-El Correo de Zamora.

Tabla 1. Magnitudes de los diarios de Castilla y León 2012-2014

\begin{tabular}{|c|c|c|c|c|}
\hline Diario de Ávila & 2015 & 2014 & 2013 & 2012 \\
\hline Cifra neta de negocio & $1.715,25$ & $1.821,00$ & & \\
\hline Resultado D.D.I. & 12,69 & 96,00 & & \\
\hline Coste por empleado & 31,68 & 36,15 & & \\
\hline Empleados & 25 & 27 & & \\
\hline Ingresos venta ejemplares & 689,02 & 701,00 & & \\
\hline Ingresos por publicidad & $1.024,14$ & $1.120,00$ & & \\
\hline Otros ingresos & 82,88 & 82 & & \\
\hline Diario de Burgos & 2015 & 2014 & 2013 & 2012 \\
\hline Cifra neta de negocio & $6.222,55$ & $6.643,82$ & $7.018,96$ & $7.820,03$ \\
\hline Resultado D.D.I. & 175,58 & 102,34 & 359,39 & 789,03 \\
\hline Coste por empleado & 49,38 & 51,34 & 49,56 & 47,92 \\
\hline Empleados & 54 & 55 & 57 & 58 \\
\hline Ingresos venta ejemplares & $3.341,44$ & $3.440,56$ & $3.700,92$ & $4.067,30$ \\
\hline Ingresos por publicidad & $2,881,11$ & $3.203,26$ & $3.318,04$ & $3.752,73$ \\
\hline Otros ingresos & 419,65 & 404,32 & 398,11 & 388,46 \\
\hline El Adelantado de Segovia & 2015 & 2014 & 2013 & 2012 \\
\hline Cifra neta de negocio & $1.748,68$ & $1.745,03$ & $1.888,65$ & $1.967,94$ \\
\hline Resultado D.D.I. & 88,60 & 196,20 & 203,64 & 200,13 \\
\hline Coste por empleado & 25,85 & 26,76 & 29,31 & 29,82 \\
\hline Empleados & 31 & 29 & 30 & 31 \\
\hline Ingresos (venta ejemplares y publicidad) & $1.748,68$ & $1.745,03$ & $1.891,95$ & $1.967,94$ \\
\hline Diario de León & 2015 & 2014 & 2013 & 2012 \\
\hline Cifra neta de negocio & $8.298,59$ & $8.266,01$ & $8.036,38$ & $8.446,77$ \\
\hline Resultado D.D.I. & 226,61 & 109,38 & 71,03 & 60,38 \\
\hline Coste por empleado & 48,51 & 48,04 & 49,27 & 50,15 \\
\hline Empleados & 66 & 65 & 68 & 71 \\
\hline Ingresos venta ejemplares & $4.445,18$ & $4.472,48$ & $4.007,10$ & $4.077,05$ \\
\hline Ingresos por publicidad & $3.229,02$ & $3.102,32$ & $3.140,96$ & $3.008,50$ \\
\hline Otros ingresos & 321,32 & 343,30 & 136,07 & 162,75 \\
\hline Diario Palentino & 2015 & 2014 & 2013 & 2012 \\
\hline Cifra neta de negocio & $2.036,06$ & $2.374,69$ & $2.032,88$ & $2.061,27$ \\
\hline Resultado D.D.I. & 6,85 & 1,64 & 215,34 & 315,13 \\
\hline Coste por empleado & 30,38 & 33,40 & 32,72 & 33,71 \\
\hline Empleados & 26 & 27 & 27 & 27 \\
\hline Ingresos (venta ejemplares y publicidad) & $2.468,11$ & $2.878,43$ & $2.306,82$ & $2.121,76$ \\
\hline El Norte de Castilla & 2015 & 2014 & 2013 & 2012 \\
\hline Cifra neta de negocio & $15.480,49$ & $15.918,54$ & $16,091,53$ & $16,681,92$ \\
\hline Resultado D.D.I. & 690,72 & 762,61 & $1.027,71$ & $1.087,33$ \\
\hline Coste por empleado & 54,85 & 55,09 & 54,43 & 57,63 \\
\hline Empleados & 109 & 109 & 109 & 96 \\
\hline Ingresos venta ejemplares & $7.804,08$ & $8.203,99$ & $8.849,91$ & $9.663,42$ \\
\hline Ingresos por publicidad & $7.676,41$ & $7.714,55$ & $7.241,62$ & $7.018,51$ \\
\hline Otros ingresos & $2.183,38$ & $2.167,02$ & $2.023,75$ & $1.973,35$ \\
\hline La Gaceta Regional de Salamanca & 2015 & 2014 & 2013 & 2012 \\
\hline Cifra neta de negocio & $9.036,98$ & $8.968,94$ & $8.620,05$ & $9.294,80$ \\
\hline Resultado D.D.I. & $1.363,27$ & $1.254,29$ & 778,18 & 739,58 \\
\hline Coste por empleado & 41,13 & 42,92 & 42,15 & 41,62 \\
\hline Empleados & 58,00 & 55,00 & 61,00 & 63,00 \\
\hline Ingresos venta ejemplares & $4.720,92$ & $4.961,69$ & $9.099,00$ & $9.544,42$ \\
\hline Ingresos por publicidad & $3.863,58$ & $3.638,73$ & & \\
\hline Otros ingresos & 536,30 & 546,10 & & \\
\hline La Opinión-El Correo de Zamora & 2015 & 2014 & 2013 & 2012 \\
\hline Cifra neta de negocio & $2.812,72$ & $2.665,16$ & $2.789,74$ & $2.845,91$ \\
\hline Resultado D.D.I. & 225,62 & 160,43 & 354,88 & 394,68 \\
\hline Coste por empleado & 30,59 & 31,95 & 32,56 & 33,74 \\
\hline Empleados & 42 & 38 & 38 & 38 \\
\hline Ingresos (venta ejemplares y publicidad) & $2.894,31$ & $2.770,86$ & \multicolumn{2}{|c|}{$2.859,952,899,57$} \\
\hline Heraldo de Soria & 2015 & 2014 & 2013 & 2012 \\
\hline Cifra neta de negocio & $1.600,39$ & $1.632,08$ & $1.595,25$ & $1.902,68$ \\
\hline Resultado D.D.I. & 134,36 & 193,68 & 256,51 & 280,07 \\
\hline Coste por empleado & 24,91 & 21,32 & 23,41 & 27,81 \\
\hline Empleados & 32 & 36 & 35 & 41 \\
\hline Ingresos (venta ejemplares y publicidad) & $1.601,00$ & $1.632,20$ & 925,25 & $1,013,68$ \\
\hline
\end{tabular}


Fuente: Elaboración propia con datos de Noticias de la Comunicación, números 340, 351, 362 y 373 (en miles de euros).

\subsection{La eclosión de los diarios digitales}

Los medios digitales han tenido un desarrollo espectacular en los últimos años. Además de los portales web de los diarios impresos, que no se han contabilizado en este mapa, su presencia ha evolucionado de los 9 registrados en 2009 a los 68 de 2016, todos ellos de carácter generalista y no temático (Gráfico 3). Las provincias de León (16), Burgos (13) y Valladolid (10) son las que mayor número poseen, mientras que Palencia (1) y Ávila (2) se encuentran en el caso contrario. Resulta llamativo que en 2009 no había rastro de digitales en las provincias de Burgos, Salamanca, Segovia, Soria o Zamora y ahora, la que menos ostenta, acumula un total de 4.

Gráfico 3. Evolución de los diarios digitales en Castilla y León 2009-2016

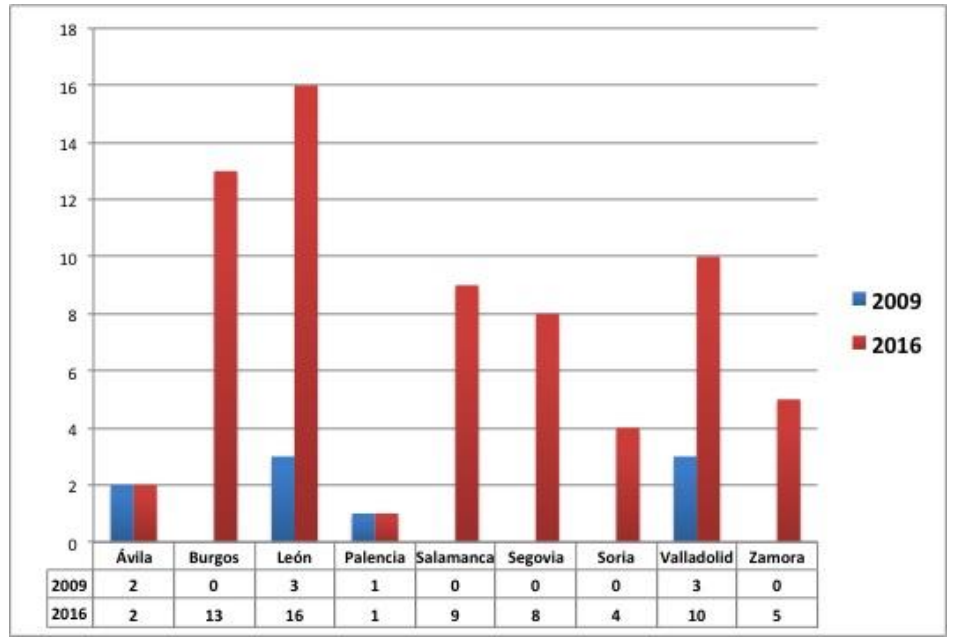

Fuente: Elaboración propia.

Destacamos la existencia de diarios con disposición regional. Se incluyen aquí los proyectos del Grupo Tribuna -surgido en Salamanca tras la desaparición de Tribuna de Salamanca, y que ha creado digitales en las nueve provincias- y Noticias de Castilla y León, con sede en la localidad vallisoletana de Laguna de Duero, y también con cabeceras en las capitales de la región. Estos diarios han computado como uno solo por tratarse de la misma empresa, adjudicándose el primero a Salamanca y el segundo a Valladolid. 
Tabla 2. Mapa provincial de los diarios digitales

\begin{tabular}{|c|c|c|c|c|c|}
\hline Ávila & \multirow{3}{*}{\multicolumn{2}{|c|}{$\begin{array}{l}\text { Avilared* } \\
\text { El Naviero }\end{array}$}} & iLeon* & Soria & Desde Soria* \\
\hline & & & Infobierzo* & & El Mirón de Soria* \\
\hline & & & Laciana Digital* & & Soria Noticias \\
\hline \multirow[t]{14}{*}{ Burgos } & \multicolumn{2}{|l|}{ Aranda Hoy } & Leonoticias & & Valonsadero \\
\hline & \multicolumn{2}{|l|}{ Burgos Dijital } & León Sur Digital* & & \\
\hline & \multicolumn{2}{|l|}{ Burgos Noticias* } & Sahagún Digital & Valladolid & Diario Crítico Castilla y León \\
\hline & \multicolumn{2}{|l|}{ Burgosconecta* } & & & El Sur de Valladolid \\
\hline & Diario de la Ribera & Palencia & Palencia Digital & & La Voz de Rioseco \\
\hline & \multicolumn{2}{|l|}{ Diario del Duero } & & & Laguna al Día \\
\hline & Lerma Hoy & $\overline{\text { Salamanca }}$ & Béjar al Día & & Más Medina \\
\hline & \multicolumn{2}{|l|}{ Merindades Hoy } & Béjar FM & & Noticias Castilla y León* \\
\hline & \multicolumn{2}{|l|}{ Noticias de Burgos* } & Béjar Información & & Periodista Digital Castilla y León \\
\hline & \multicolumn{2}{|l|}{ Pinares Noticias } & Béjar Noticias & & Pisuerga Valladolid \\
\hline & \multicolumn{2}{|l|}{ Ribera Aranda } & Ciudad Rodrigo & & Pueblos y Comarcas \\
\hline & \multicolumn{2}{|l|}{ Siete Semanal } & iBéjar & & Último Cero \\
\hline & \multirow[t]{2}{*}{ Vive Miranda } & & La Crónica de Salamanca & & \\
\hline & & & Más Salamanca & Zamora & interbenavente.es* \\
\hline \multirow[t]{10}{*}{ León } & \multirow{2}{*}{\multicolumn{2}{|c|}{$\begin{array}{l}\text { Astorga Digital* } \\
\text { Astorga Redacción* }\end{array}$}} & Tribuna de Salamanca & & Zamora 24 horas \\
\hline & & & & & Zamora 3.0 \\
\hline & \multirow{2}{*}{$\begin{array}{l}\text { Bembibre Digital } \\
\text { Bierzo Diario }\end{array}$} & Segovia & Acueducto2 & & Zamora digital \\
\hline & & & Cuéllar7 & & Zamoranews* \\
\hline & Digital de León* & & El Espinar Información & & \\
\hline & \multicolumn{2}{|l|}{ El Bierzo Digital* } & ElEspinar.info & & \\
\hline & \multicolumn{2}{|l|}{ El Bierzo Noticias } & esCuéllar & & \\
\hline & \multicolumn{2}{|l|}{ El Cabreirés } & Segovia al Día & & \\
\hline & \multicolumn{2}{|l|}{ Esleon Diario* } & Segovia Audaz & & \\
\hline & & Zoquejo & & \\
\hline
\end{tabular}

Fuente: Elaboración propia. *Diarios controlados por la Oficina de Justificación de la Difusión, OJD Interactiva.

De las 68 publicaciones contabilizadas (Tabla 2), solo 18 están controladas por la Oficina de Justificación de la Difusión Interactiva -ninguna de las provincias de Palencia, Salamanca o Segovia, y solo una de Valladolid-. Sorprendentemente, de los nueve diarios impresos analizados más arriba, tampoco están controladas las versiones en la Red de El Norte de Castilla, La Opinión-El Correo de Zamora y Heraldo de Soria. En febrero de 2017, según la OJD Interactiva, el digital que más visitas recibió fue iLeon (712.242), seguido de infobierzo (416.587), Noticias de Castilla y León (328.333), Desde Soria (282.623) o El Bierzo Digital (281.917). Alguno de ellos anotó más visitas que la edición online del diario impreso de su correspondiente provincia. En esta situación se encuentra Avilared, con 207.612, mientras que Diario de Ávila se estancó en 166.692. Otros digitales que están por encima de las 100.000 visitas son Burgosconecta (178.137), Zamoranews (140.752) e interbenavente (110.391). El que menos registró fue Esleon Diario (2.776).

La mayoría de los digitales son de nueva creación, pero en algunos casos se ha producido una migración del formato papel al digital. Es lo que ha sucedido con parte de los enclavados en León, provincia muy activa en el soporte digital. Otros comenzaron como blogs y mutaron a diarios, como Burgos Dijital. Este, al igual que Último Cero, de Valladolid, ofrece información 
alternativa y no inserta publicidad. Para mantenerse, la asociación Sello Cultura, editora del burgalés, recurre a voluntarios. El vallisoletano, creado por un grupo de profesionales de la información, tiene abierta una línea de apoyo para que los lectores hagan aportaciones económicas que permitan sostener el proyecto.

En Burgos tuvo lugar la única experiencia de periodismo ciudadano con la creación, en 2010, del diario BurgosHoy, un portal de la red nacional de PeriodistasHoy caracterizado por ofrecer sitios web de información local hecha por y para los ciudadanos. En este medio, cualquier persona podía registrarse para publicar su propia noticia. La experiencia resultó fallida y dejó de actualizarse en 2016 (Martínez y Monteserín, 2011: 269).

\subsection{La fortaleza de la radio}

Los principales grupos de comunicación radiofónicos tienen implantación en esta Comunidad. Radio Nacional de España (RNE 1 y Radio 5 Todo Noticias) es la que mayor número de emisoras acapara, 39, seguida de la Cadena Ser, con 22 -es la tercera Comunidad de España que concentra un mayor númeroy la Cope y Onda Cero, con 21, respectivamente (SGAE, 2016). Por lo que se refiere a la radio musical, los castellanos y leoneses pueden escuchar las emisoras públicas Radio Clásica y Radio 3 (35); las del Grupo Prisa Radio: 40 Principales (11), Cadena Dial (10) y M80 (3); las del Grupo Cope: Cadena 100 (11 emisoras, las más numerosas de toda España) y Rock FM (3), y las del Grupo Planeta: Europa FM (6) y Melodía FM (7). En total, 189 emisoras (103 generalistas y 86 musicales).

Con respecto a 2009, su número ha disminuido en un 20,3\%. Entonces, sumaban 237, 141 generalistas y 96 musicales (SGAE, 2010). Precisamos que no se han contabilizado las 13 emisoras de que disponía Punto Radio en 2009, puesto que la cadena desapareció en marzo de 2013. Vocento, propietaria de la cadena, llegó a un acuerdo nacional con la Cope, que se hizo con estas emisoras. 
Gráfico 4. Implantación de los principales grupos radiofónicos en Castilla y León 2009-2015

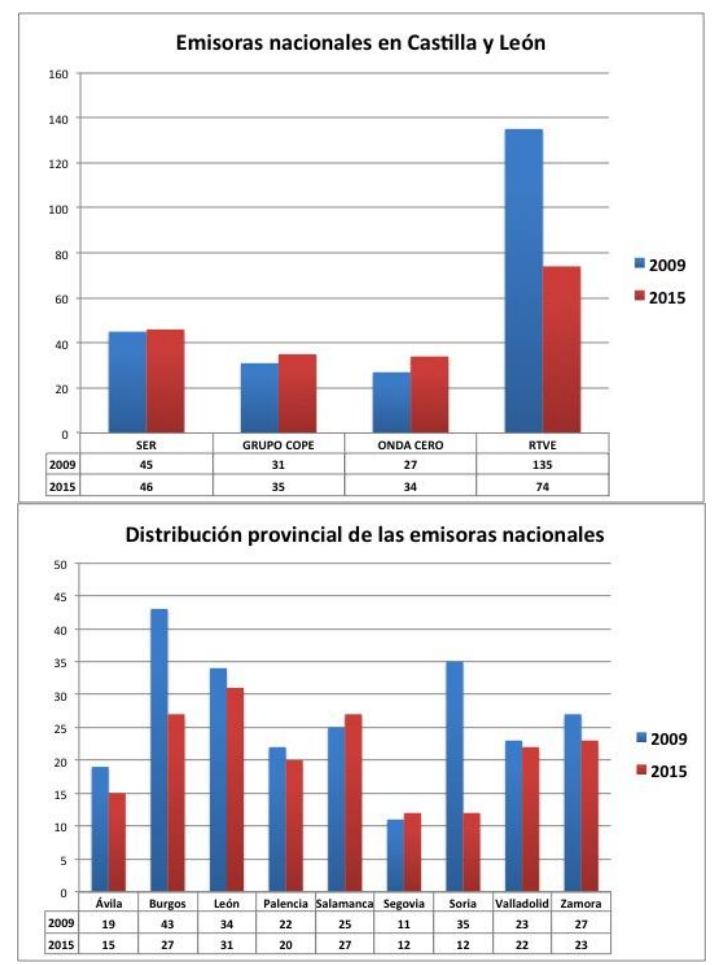

Fuente: Elaboración propia a partir de los datos de los Anuarios de la Sociedad General de Autores y Editores (SGAE) 2010 y 2016.

La distribución provincial de estas emisoras es asimétrica (Gráfico 4), de forma que nos encontramos con provincias como León (31), Burgos (27) o Salamanca (27), que aglutinan al mayor número, a otras como Segovia o Soria, que son, con 12, las que menos tienen. Otras marcas de menor calado también se asientan en este territorio, como esRadio (16), Radio María (28), Kiss FM (12), Intereconomía (3) o Radio Marca (3).

Castilla y León fue la Comunidad Autónoma que más minutos de radio diarios consumió en 2015, 117 minutos, junto con el País Vasco y La Rioja (SGAE, 2016). En el otro extremo se situaría Andalucía, con 96. Entre la radio generalista o musical, los castellanos y leoneses prefieren sintonizar la primera, a la que destinaron el 56\% de su tiempo de escucha. Curiosamente, en 2009, los minutos reservados a la radio fueron 117 igualmente. 
Si analizamos la cuota autonómica de las cadenas de radio generalista, cabe afirmar que de cada 100 oyentes que sintonizaron la Ser, 8,3 lo hicieron desde Castilla y León, lo que la convierte, junto con Cataluña, en la cuarta Comunidad que más escucha esta emisora. Este mismo lugar en el ranking se repite en el caso de la cuota regional de la Cope $(9,1)$, de Onda Cero $(8,5)$ y RNE (9,7). En el caso de esRadio, la cuota de Castilla y León sube hasta el 11,9, por lo que ocupa la tercera posición, tras Madrid y Valencia (SGAE, 2016). Las cuotas en Castilla y León en 2009 se repartían así: 8,0 en la Ser; 6,6 Onda Cero; 10,0 la Cope; 7,5 RNE, y 12,3 Punto Radio (SGAE, 2010).

Gráfico 5. Audiencia de la radio generalista en Castilla y León 2009-2015

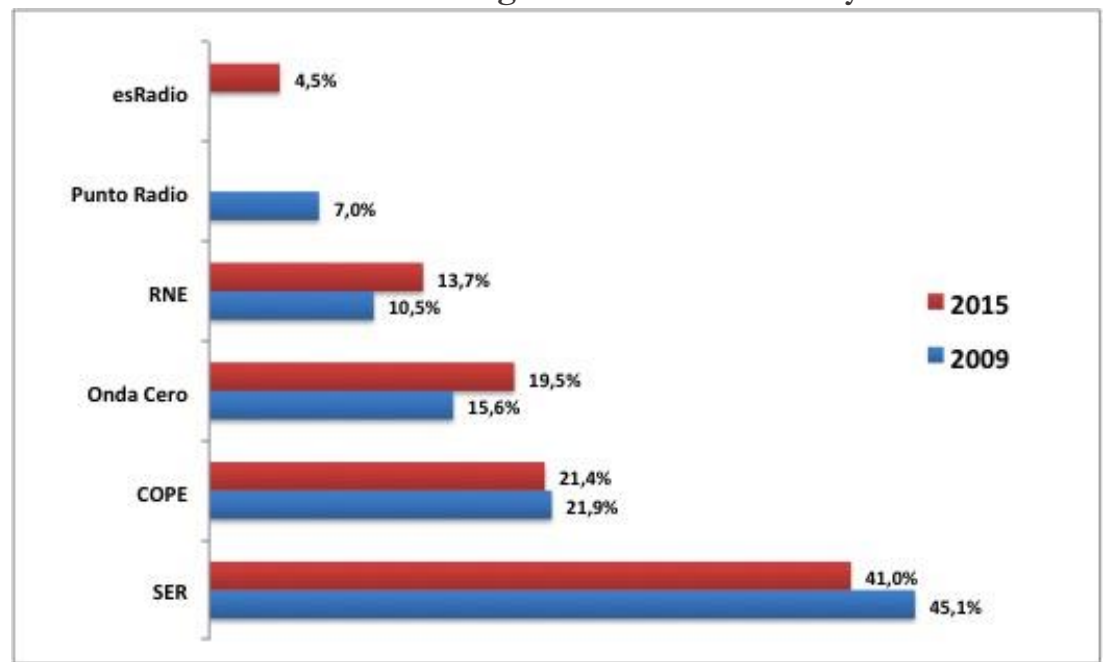

Fuente: Elaboración propia con datos de los Anuarios de la SGAE 2010 y 2016. Audiencia según el promedio de oyentes de las tres oleadas de 2009 y 2015 del EGM.

La audiencia castellano y leonesa se decanta mayoritariamente por la Ser, con un share del 41,0\%, un 4,1\% menos que en 2009 (Gráfico 5). Le sigue, a gran distancia, la Cope, con el 21,4\% y la pérdida de un $0,5 \%$ de oyentes; Onda Cero, con el 19,5\%, ha ganado terreno en los últimos años, igual que RNE, que se sitúa en el 13,7\%. En 2009, la extinta Punto Radio tenía una audiencia del 7\% y la nueva emisora esRadio, que se ponía en marcha en septiembre del mencionado año con Jiménez Losantos, César Vidal y Luis Herrero, presentaba una audiencia del 4,5\% en 2015. 


\subsection{La reestructuración de la televisión}

El censo de las televisiones en Castilla y León apenas ha sufrido variación desde 2009, año en el que comenzó a emitir la nueva televisión regional, Radio Televisión de Castilla y León, RTVCYL. A principios del mencionado ejercicio, el Gobierno regional, que nunca apostó por un operador público, adjudicó la cadena autonómica de carácter privado a la sociedad constituida al 50\% por los Grupos Promecal y Begar. Hasta entonces, estas empresas competían por posicionar sus televisiones, el primero a través de Canal 4 Castilla y León, y el segundo con la Televisión Castilla y León. De hecho, la Sociedad adjudicataria del concurso fue el resultado de la fusión de estas dos redes preexistentes de televisiones locales en la región.

En 1998 nació Televisión Castilla y León, con 12 emisoras que en 2006 se ampliaron hasta 18. Al principal accionista, el propietario de Begar Construcciones, le acompañaban Caja España, Inversiones Palazuelo, El Norte de Castilla, Raimcomsa, Otecable, Caja Burgos y unos 50 socios locales (Iglesias, 2006: 29). Ese mismo año, Méndez Pozo crea la Sociedad Canal 4 Castilla y León. Para entonces, ya era propietario de las televisiones de Palencia, Burgos y Valladolid. La idea de levantar una televisión en cada provincia surgió a raíz del acuerdo al que llega con Antena 3 Televisión para gestionar y producir contenidos regionales de la cadena en Castilla y León. De esta forma, comienza la implantación de teles provinciales a modo de corresponsalías, dando así lugar a Canal 4 Castilla y León (Badillo, 2003: 238240).

Bajo las denominaciones de CyL7 y CyL8, el 9 de marzo de 2009 comenzaron las emisiones de los nuevos canales de la televisión regional, hecho que supuso el fin de las emisiones de Canal 4 y Televisión Castilla y León. La programación regional se emitió a través de la frecuencia única de CyL7, y CyL8 se reservó para las desconexiones locales (Calvo, 2016: 155). Actualmente, pues, cada provincia de la región dispone de la marca La8 CyLTV. León cuenta con 2, una en la capital y otra en Ponferrada. En Valladolid se asientan, además, CyL7, Antena 3 TV, el Centro Territorial de RTVE y Televisión Medina del Campo. Otras provincias que además del canal local autonómico disponen de otras televisiones son Burgos (Canal 54 y Tele Aranda) y Zamora (TV Benavente). Añadimos que la tele online también se ha establecido en algunos lugares: Burgos TV, Salamanca RTV al día y Soria TV estas televisiones no se han contabilizado en el Gráfico 6-.

Así está ahora el mapa televisivo desde que Televisión Segovia (Badillo, 2003: 212), la decana de la región, comenzara sus emisiones de forma estable en 
1989. Apenas 13 años después de aquel estreno, se contabilizaban 35 emisoras de televisión, que crecieron hasta 37 en 2006 (Iglesias, 2006: 72-77). Posteriormente, en el estudio de 2008 coordinado por Celso Almuiña, las televisiones locales habían aumentado hasta 40. A partir de entonces, el sector ha sufrido una importante reestructuración, achacable, por un lado, a la crisis económica, que se saldó con el cierre de las televisiones de Localia (Grupo Prisa), Popular TV (Grupo Cope) u otras de iniciativa empresarial local, y, por otro, a la política de comunicación de la Junta de Castilla y León, que obligó a los grupos Promecal y Edigrup Media a entenderse para concurrir de forma conjunta a la convocatoria del canal autonómico. Una de las consecuencias de esta apuesta conllevó la supresión de varias televisiones locales por la duplicidad que se producía en algunos territorios.

El censo actual lo conforman 17 televisiones, frente a las 23 que aparecían en la Guía de la Comunicación de 2009. La provincia que mayor número ha perdido en estos últimos años ha sido Salamanca, que pasa de cuatro a una cerraron TV Ciudad Rodrigo-Vitigudino, Localia y TV Comarcal Peñaranda-. En Burgos y en Segovia desapareció Popular TV, y en Soria, Tele Almazán. Provincias como Ávila, León, Palencia, Valladolid o Zamora conservan los mismos canales que en 2009.

Gráfico 6. Número de televisiones en Castilla y León 2009-2016

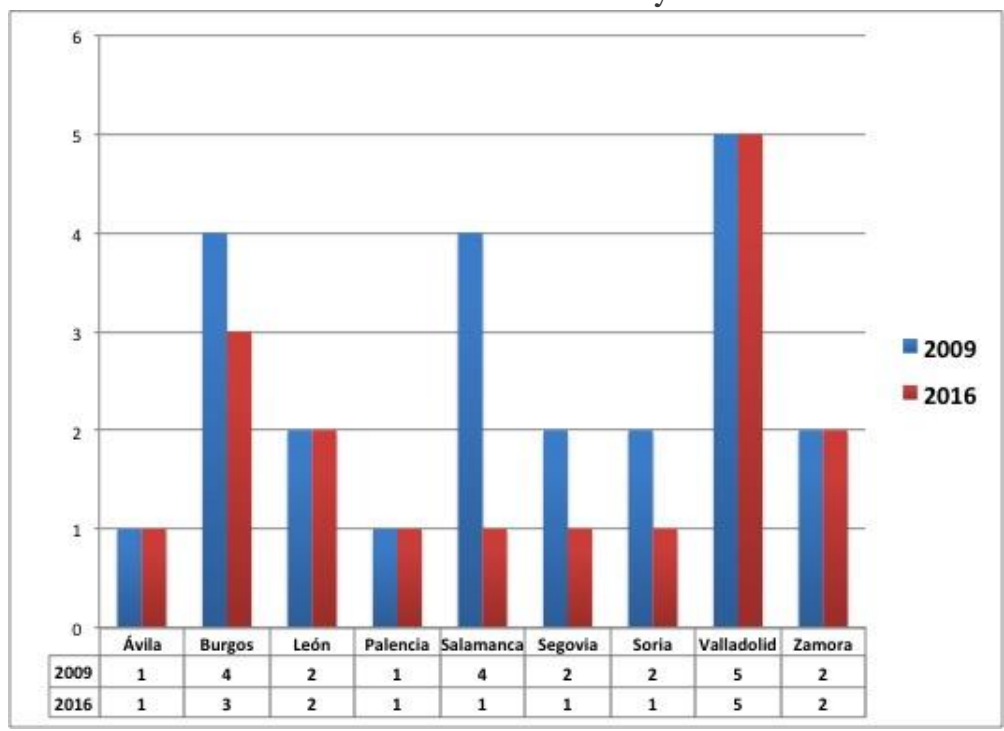

Fuente: Elaboración propia. 
Los contenidos regionales y provinciales han quedado prácticamente en manos del canal autonómico privado, pues el Centro Territorial de Castilla y León tan solo produce dos informativos diarios de 25 y 10 minutos, respectivamente (Pérez, 2016: 237). TVE disminuyó en 2004 de forma considerable la información de proximidad, reducción que se acentuó con la pérdida de efectivos en 2005, año en el que se llevó a cabo un Expediente de Regulación de Empleo (ERE) y la creación de las unidades informativas. La presencia de la televisión pública en las provincias se mantiene atendida, a modo de corresponsalías, por los propios redactores de RNE. En algunos casos, incluso, las noticias provinciales se cubren con el desplazamiento de redactores o cámaras de Valladolid al lugar de los hechos.

De 2009 a 2015 el consumo televisivo diario en Castilla y León fue muy superior a la media española (Gráfico 7). Sin embargo, en 2016 prácticamente se igualó al experimentar una fuerte caída hasta los 225 minutos -la media en España era de 223 minutos-. Por encima de esta Comunidad se posicionan La Rioja (258), Extremadura (251), Asturias (250), Aragón (245), Castilla La Mancha (240), Canarias (233), Andalucía (229) y la Comunidad Valenciana (228). Baleares (166) y Murcia (198) registran el menor consumo televisivo (AIMC, 2017).

Gráfico 7. Evolución del consumo de televisión en Castilla y León 20092016

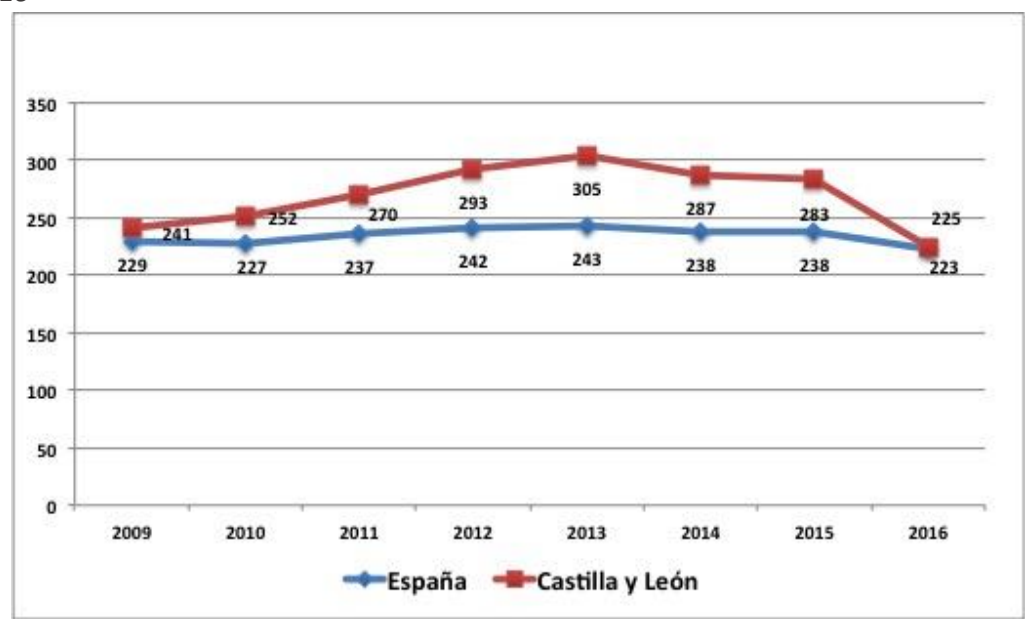

Fuente: Elaboración propia con datos del Marco General de los Medios en España 2017. AIMC. Minutos promedio de visionado.

De cara a conocer las predilecciones de los castellanos y leones para sintonizar una u otra cadena de televisión, hemos comparado el tramo temporal 2010- 
2016. Recordemos que el canal autonómico privado no comenzó a emitir hasta marzo de 2009, de forma que hasta un año después no es posible facilitar índices de audiencia. Tanto en 2010 como en 2016, las televisiones preferidas fueron Antena 3, TVE 1 y Telecinco, con cambios en el ranking en función de que se contemple uno u otro año (Gráfico 8). Le siguen La Sexta, Cuatro y La 2 y, finalmente, CyL7 y CyL8, cuyo consumo tiende a la baja: de representar el 2,5\% en 2010 al 2,1\% en 2016. De este último porcentaje, a la primera le corresponde un 1,4\% y a la segunda un $0,7 \%$ (Kantar Media, 2010, 2016).

Gráfico 8. Share de las cadenas de televisión en Castilla y León 20102016

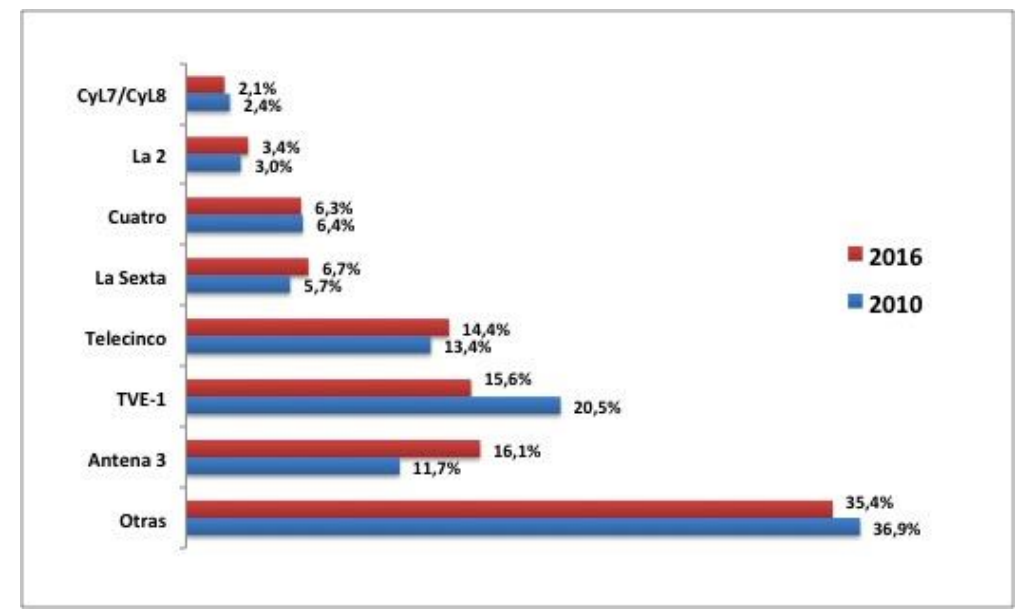

Fuente: Elaboración propia con datos de Kantar Media. Porcentaje sobre el total de espectadores (share).

\section{Desempleo y precariedad laboral}

El efecto de la crisis para los profesionales de los medios de comunicación ha sido devastador. El Colegio de Periodistas de Castilla y León estima que de 2008 a 2015 se han destruido 405 puestos de trabajo. En España, habrían sido 12.200 empleos de todo tipo los que se habrían perdido, de los que solo una parte son periodistas, según el Informe Anual de la Profesión Periodística 2015 realizado por la Asociación de la Prensa de Madrid. Los dos colectivos profesionales advierten de que estas cifras han de tomarse como mínimas, ya que no trascienden todos los conflictos laborales que terminan saldándose con merma de empleo y es muy difícil conocer lo ocurrido en los medios pequeños, y especialmente los del ámbito local. 
El paro registrado en Castilla y León durante 2016 fue de 349 periodistas (227 mujeres y 122 hombres), cuando el total nacional alcanzó los 7.890 desempleados (5.029 mujeres y 2.861 hombres). Esta Comunidad ocupa la séptima posición, después de otras como Madrid, Andalucía, Cataluña, la Comunidad Valenciana, País Vasco y Galicia. Con respecto a 2015, el paro se redujo en Castilla y León por encima de la media, un 13,8\%, cuando en España lo hizo un $9,1 \%$.

Los conflictos laborales más importantes que se han vivido en Castilla y León por el número de afectados se plasman en la Tabla 3. La crisis se ha cebado especialmente con los trabajadores de los medios impresos, que son los que en mayor número engrosan la lista de desempleados, en unos casos por el cierre de las publicaciones y en otros por recortes de plantilla. Como consecuencia de estas situaciones, fueron despedidos 128 profesionales (61,8\%). Les siguen, en importancia numérica, los 57 de la televisión autonómica (27,5\%), los 16 de los diarios digitales $(7,7 \%)$ y los 6 de la radio y las agencias, 3 en cada caso ( $2,8 \%$ en total). Por años, han sido los primeros de la crisis, de 2008 a 2012, donde se registra una mayor destrucción de empleo, 115, frente a los 92 de 2013. Por grupos de comunicación, la sociedad formada por PromecalEdigrup Media lidera los despidos, seguida de los Grupos Proyectos Editoriales de Salamanca, Publicaciones Regionales y Propelesa. El Grupo Promecal, Gente y el Adelantado de Segovia cierran esta lista.

Tabla 3. Destrucción de empleo en Castilla y León 


\begin{tabular}{|c|c|c|}
\hline DESTRUCCIÓN DE EMPLEO & 2008-2012 & 2013 \\
\hline \multicolumn{3}{|l|}{ CIERRE PERIÓDICOS } \\
\hline La Crónica de León & & 30 \\
\hline El Adelanto (Salamanca) & & 30 \\
\hline La Tribuna de Salamanca & 32 & \\
\hline Áviladigital.com & 5 & \\
\hline Elacueducto.com (Segovia) & 11 & \\
\hline \multicolumn{3}{|l|}{ RECORTES PERIÓDICOS } \\
\hline Diario de Ávila & 8 & \\
\hline La Gaceta Regional de Salamanca & 7 & 3 \\
\hline El Adelantado de Segovia & & 3 \\
\hline El Día de Valladolid & 8 & \\
\hline Gente en Ávila & 4 & \\
\hline Gente en Valladolid & & 3 \\
\hline \multicolumn{3}{|l|}{ RECORTES RADIO } \\
\hline Radio Salamanca & & 2 \\
\hline Radio Popular Segovia & 1 & \\
\hline \multicolumn{3}{|l|}{ RECORTES TELEVISIÓN } \\
\hline RTVCYL & 37 & 20 \\
\hline \multicolumn{3}{|l|}{ RECORTES AGENCIAS } \\
\hline Servicio de Páginas Comunes (Valladolid) & 2 & \\
\hline ICAL (Salamanca) & & 1 \\
\hline TOTAL & 115 & 92 \\
\hline
\end{tabular}

Fuente: Elaboración propia con los datos del Informe Anual de la Profesión Periodística 2015. Asociación de la Prensa de Madrid (APM). Observaciones: los datos recogidos no contemplan toda la destrucción de empleo en Castilla y León, sino los conflictos laborales más importantes por el número de afectados.

La Asociación de la Prensa de Valladolid (APV) puso en marcha un Observatorio sobre los efectos de la crisis en el periodismo. Según los datos recabados, la provincia vallisoletana habría perdido, en el periodo 2007-2012, 170 empleos, y en 2013, 175, donde se incluirían redactores, técnicos, maquetadores o fotógrafos, siendo el sector de la prensa el más vapuleado. En las encuestas que la APV ha venido realizando a sus asociados para conocer su situación, los periodistas opinan que la crisis ha provocado, además de una mayor precariedad, un empeoramiento en la calidad de la confección de las noticias y la pérdida de independencia profesional y de pluralidad informativa. Confiesan que sus condiciones laborales son peores cada año y que temen por su puesto de trabajo. 
Envidiables resultan ahora, con la perspectiva que ofrece el paso del tiempo, las conclusiones de los estudios realizados por Almuiña et al. (2006) e Iglesias (2006) sobre los periodistas en Castilla y León. En 2003, estos profesionales gozaban de cierta estabilidad en sus empresas, dado que el 74\% tenía contratos fijos y el 95\% vivía de un salario, sin que existiera apenas el trabajador autónomo. Hoy en día, según el Anuario de la Profesión Periodística 2016, el $26,8 \%$ de los periodistas españoles trabaja como autónomo.

\section{Conclusiones}

La primera conclusión que cabe extraer de este estudio es la necesidad de crear en Castilla y León un Observatorio de la Comunicación que permita obtener datos rigurosos y fiables del estado de los medios de comunicación regionales. Una herramienta de esta naturaleza se antoja imprescindible en los momentos actuales, cuando los medios de comunicación están sufriendo un giro de 180 grados.

El ecosistema mediático castellano y leonés ha cambiado de forma considerable en los últimos años como consecuencia de un implacable ajuste motivado por la crisis económica y por su propio modelo de negocio. Se ha confirmado el cierre de algunos diarios en papel prensa y la aceleración hacia los medios digitales. De las 50 publicaciones existentes en 2009 se ha pasado a 42 -un 16\% menos-, y los diarios digitales han crecido exponencialmente: de 9 a 68 -un 86,8\% más-. Igualmente, es persistente la erosión de las cifras de negocio de los nueve principales diarios analizados, sus ingresos publicitarios y venta por ejemplar, al igual que su difusión, que sufrió un desplome del $32,28 \%$ desde el año anterior a la crisis, 2007, hasta 2015.

Ninguno de ellos se posiciona ya entre los que tienen una difusión superior a los 25.000 ejemplares y solo tres están por encima de los 10.000. Las provincias de Salamanca, donde cerraron El Adelanto y Tribuna de Salamanca, y León, con la desaparición de La Crónica de León, fueron las más afectadas. Esta situación se ha intentado paliar con la puesta en marcha de proyectos digitales: León es la más dinámica -algunos títulos son resultado de la migración de formatos papel a digital-, y en Salamanca, a la Tribuna papel le sustituyó la Tribuna digital con presencia en toda Castilla y León.

El segundo sector más tocado por la crisis ha sido la televisión, que pasó de las 40 emisoras en 2008 a las 17 actuales. En estos cierres se contabilizan los de Localia o Popular TV, pero también iniciativas empresariales particulares. Además, en 2009 arrancaron las emisiones de RTVCYL, lo que acabó por 
reestructurar esta industria. Su consumo se ha retraído en los últimos años y el share de CyL7 y CyL8 ha caído del 2,4 de 2010 al 2,1\% de 2016.

Tanto en prensa como en televisión se produce una extraordinaria y creciente concentración de medios en manos de los grupos Promecal y Edigrup Media. Ambos explotan al 50\% la televisión autonómica y son los propietarios de buena parte de los periódicos con mayor influencia que se publican en la Comunidad. En radio, sin embargo, pese a que estos grupos cuentan con frecuencias radiofónicas, son los medios nacionales quienes lideran una mayor implantación: el grupo Prisa, con la Ser; la Conferencia Episcopal, con la Cope; Planeta, con Onda Cero, y RTVE, con Radio Nacional de España. El medio radiofónico es el único que sube en audiencia en los años que analizamos y los castellanos y leoneses son, del conjunto nacional, los que más minutos la escuchan diariamente. Además, se decantan claramente por la cadena Ser, a la que sigue en audiencia la Cope, Onda Cero, RNE y esRadio.

La crisis económica ha azotado con dureza a la profesión periodística, especialmente al ámbito de la prensa seguido por el de la televisión. El Colegio de Periodistas de Castilla y León cifra en 405 los trabajadores de los medios de comunicación que habrían perdido su empleo, si bien la propia organización es consciente de que esta cifra podría ser superior. Igualmente, se constata la precarización de las condiciones laborales del colectivo, que está acarreando una pérdida en la calidad y pluralidad informativa.

\section{Bibliografía}

AIMC. (2010-2017). Marco General. Madrid: AIMC.

Almuiña, C. et al. (2006). Radiografía de la profesión periodística en Castilla y León. Valladolid: Junta de Castilla y León y Universidad de Valladolid.

Asociación de la Prensa de Madrid. (2016). Anuario de la Profesión Periodística 2016. Madrid: APM.

Badillo Matos, Á. (2003). La desregulación de la televisión local en España: el caso de Castilla y León [Tesis Doctoral]. Barcelona: Universidad Autónoma de Barcelona. Recuperado de: http://www.tdx.cat/handle/10803/4115

- (2011). Modelos de clivaje público-privado de la televisión subnacional en España. En adComunica. Revista Científica de Estrategias. Tendencias e Innovación en Comunicación, $\mathrm{n}^{\circ}$ 1, pp. 63-81. Castellón: Asociación para el 
desarrollo de la Comunicación adComunica, Universidad Complutense de Madrid y Universidad Jaume I.

Calvo, M. (2016). 83 años de ondas en Burgos. En 100 años contando lo que ocurre en Burgos. Primer centenario de la Asociación de la Prensa de Burgos, pp. 119-158. Burgos: Diputación Provincial de Burgos.

Chomón Serna, J. M. (2011). Evolución y transformaciones de Radio 5 Todo Noticias. Una radio menos cercana. Madrid: Fragua.

Consejo Económico y Social de Castilla y León. (2008). La relevancia de los Medios de Comunicación en Castilla y León. Informe a Iniciativa Propia IIP. Valladolid: Consejo Económico y Social de Castilla y León. Recuperado de: http://www.cescyl.es/es/publicaciones/informes-iniciativa-propia/informeiniciativa-propia-relevancia-medios-comunicacion-ca

Díaz-González, M. J. (2006). El sistema de medios en Castilla y León: el caso de Segovia. En Comunicación local: da pesquisa á producción. Actas do Congreso Internacional Lusocom. Santiago de Compostela. Recuperado de: https://dialnet.unirioja.es/servlet/articulo?codigo $=2064091$

- y otros (2008). La Radio en Castilla y León: Política y estructura desde el Estatuto de Autonomía. En Actas del Congreso fundacional de la AEIC. I+C Investigar en Comunicación. Santiago de Compostela. Recuperado de: https://dialnet.unirioja.es/servlet/articulo?codigo $=3284099$

Fundación Telefónica. (2016). La sociedad de la información en España 2016. Madrid: Fundación Telefónica. Recuperado de: http://www.fundaciontelefonica.com/arte_cultura/publicacioneslistado/pagina-item-publicaciones/itempubli/558/

Gómez-Escalonilla, G. (2004). Periodismo digital: Nuevas exigencias para el profesional de la información. Redes.com (1), 61-72.

González del Valle, A. et al. (2010). El sector radiofónico en Castilla y León. Emisoras, oyentes y anunciantes en un momento de cambio. En Comunicación y desarrollo en la era digital. Actas del Congreso AE-IC. Recuperado de: https://dialnet.unirioja.es/servlet/articulo?codigo $=3960988$

Guía de la Comunicación de Castilla y León, (2009). Valladolid: Junta de Castilla y León. 
Iglesias, Z. (2006). La información de televisión local: las emisoras de Castilla y León. Madrid: Fragua.

Kantar Media. (2010-2016). Anuario de Audiencia de Televisión 2010. Madrid: Kantar Media.

Martínez, L. y Monteserín, P. (2011). El periodismo ciudadano como herramienta de democratización de los medios informativos digitales: caso práctico de Burgoshoy. En J. J. Verón y F. Sabés (Coords.), La investigación en periodismo digigal: algunos trabajos desde el ámbito universitario, pp. 261 270 . Recuperado de: https://dialnet.unirioja.es/servlet/articulo?codigo $=3623448$

Noticias de la Comunicación, mensual (ediciones de los años 2009-2016). Madrid: Noticias de la Comunicación.

Ortega Mohedano, F. (2006). El sector audiovisual en Castilla y León [Tesis doctoral]. Salamanca: Universidad de Salamanca.

Pérez, M. (2015). La televisión de proximidad en el ámbito autonómico, el caso de TVE Castilla y León 1982-2012. (Tesis inédita de doctorado). Universidad de Burgos, Burgos.

SGAE. (2010-2016). Anuario de las Artes Escénicas, Musicales y Audiovisuales. Madrid: SGAE.

Tamarit, A. (2006). Periodistas locales: el caso de Castilla y León. Madrid: Fragua. 


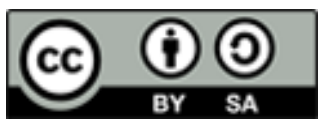

Licencia Creative Commons

Miguel Hernández Communication Journal

mhjournal.org

\section{Cómo citar este texto:}

Clara Sanz Hernando (2017): “La migración digital y la crítica situación de la prensa y televisión marcan el ecosistema informativo de Castilla y León”, en Miguel Hernández Communication Journal, nº, pp. 617 a 642. Universidad Miguel Hernández, UMH (ElcheAlicante). Recuperado el $\_$de mhjournal.org] de 20_ de: Џink del artículo en 